\title{
Pediatric bipolar disorder and ADHD: Family history comparison in the LAMS clinical sample
}

\author{
L. Eugene Arnold ${ }^{\mathrm{a},}{ }^{,}$, Katherine Mount ${ }^{\mathrm{a},{ }^{* *}}$, Thomas Frazier $^{\mathrm{b}}$, Christine Demeter ${ }^{\mathrm{c}}$, Eric A. \\ Youngstrom $^{d}$, Mary A. Fristad ${ }^{\mathrm{a}}$, Boris Birmaher ${ }^{\mathrm{e}}$, Sarah Horwitz ${ }^{\mathrm{f}}$, Robert L. Findling ${ }^{\mathrm{c}}$, \\ Robert Kowatch $^{\mathrm{g}}$, and David Axelson ${ }^{\mathrm{e}}$ \\ aDivision of Child and Adolescent Psychiatry, Department of Psychiatry, Ohio State University, \\ Columbus, OH, United States \\ ${ }^{b}$ Center for Pediatric Behavioral Health and Center for Autism, Cleveland Clinic, Cleveland, $\mathrm{OH}$, \\ United States \\ 'Division of Child and Adolescent Psychiatry, Department of Psychiatry, Case Western Reserve \\ University, Cleveland, $\mathrm{OH}$, United States \\ ${ }^{\mathrm{d} D e p a r t m e n t}$ of Psychology, University of North Carolina at Chapel Hill, Chapel Hill, NC, United \\ States \\ eDepartment of Psychiatry, Western Psychiatric Institute and Clinic, University of Pittsburgh \\ Medical Center, Pittsburgh, PA, United States \\ fDepartment of Pediatrics and Stanford Health Policy, Stanford University School of Medicine, \\ Stanford, CA, United States \\ 'Child and Adolescent Psychiatry, Ohio State University, and Nationwide Children's Hospital, \\ Columbus, $\mathrm{OH}$, United States
}

\begin{abstract}
Background-Transgenerational association of bipolar spectrum disorder (BPSD) and attention deficit/hyperactivity disorder (ADHD) has been reported, but inconclusively.

Method-Children ages 6-12 were systematically recruited at first outpatient visit at 9 clinics at four universities and reliably diagnosed; 621 had elevated symptoms of mania ( $>12$ on the Parent General Behavior Inventory 10-Item Mania Scale); 86 had scores below 12. We analyzed baseline data to test a familial association hypothesis: compared to children with neither BPSD nor ADHD,
\end{abstract}

\footnotetext{
(C) 2012 Published by Elsevier B.V.

*Corresponding author. Tel.: +1 614292 9780, +1 6145611429 (Cell). L.Arnold@ osumc.edu. ${ }^{* *}$ Corresponding author. Tel.: +1 614 293 9197; fax: +1 614293 4949.Katherine.Mount@ osumc.edu.

Conflict of interest statement

Dr. Arnold receives or has received research support and/or consulting honoraria from Lilly, Shire, CureMark, Neuropharm, Targacept, AstraZeneca, Novartis, Pfizer, and Seaside Therapeutics. Dr. Frazier has received federal funding or research support from, acted as a consultant to, or received travel support from Shire Development, Inc., Bristol-Myers Squibb, National Institute of Health, and Brain and Behavior Research Foundation. Dr. Youngstrom has received travel support from Bristol-Myers Squibb and consulted with Lundbeck. Dr. Findling receives or has received research support, acted as a consultant and/or served on a speaker's bureau for Abbott, Addrenex, Alexza, AstraZeneca, Biovail, Bristol-Myers Squibb, Dainippon Sumitomo Pharma, Forest, GlaxoSmithKline, Johnson \& Johnson, KemPharm Lilly, Lundbeck, Merck, Neuropharm, Novartis, Noven, Organon, Otsuka, Pfizer, Rhodes Pharmaceuticals, Roche, Sanofi-Aventis, Schering-Plough, Seaside Therapeutics, Sepracore, Shionogi, Shire, Solvay, Sunovion, Supernus Pharmaceuticals, Transcept, Validus, and Wyeth. Dr. Kowatch acted as a consultant for Forest (DSMB) and REACH Foundation, received research support from the National Institute of Child Health and Human Development, is an editor for Current Psychiatry, and is employed by The Ohio State University. Drs. Horwitz, Fristad, Birmaher, \& Axelson and Mss. Mount and Demeter have no conflicts to disclose.
} 
those with either BPSD or ADHD would have parents with higher rates of both bipolar and ADHD symptoms, and parents of comorbid children would have even higher rates of both.

Results-Of 707 children, 421 had ADHD without BPSD, 45 BPSD without ADHD, 117 comorbid ADHD+BPSD, and 124 neither. The rate of parental manic symptoms was similar for the comorbid and BPSD-alone groups, significantly greater than for ADHD alone and "neither" groups, which had similar rates. ADHD symptoms in parents of children with BPSD alone were significantly less frequent than in parents of children with ADHD (alone or comorbid), and no greater than for children with neither diagnosis. Family history of manic symptoms, but not ADHD symptoms, was associated with parent-rated child manic-symptom severity over and above child diagnosis.

Limitations-The sample was not epidemiologic, parent symptoms were based on family history questions, and alpha was 0.05 despite multiple tests.

Conclusions-These results do not support familial linkage of BPSD and ADHD; they are compatible with heritability of each disorder separately with coincidental overlap.

\section{Keywords}

Bipolar disorder; ADHD; Family history

\section{Introduction}

Both bipolar spectrum disorder (BPSD (including BP I, BP II, cyclothymic disorders, and bipolar disorder not otherwise specified) and attention deficit/hyperactivity disorder (ADHD) manifest symptoms of impulsivity, hyperactivity, and irritability, with impairments in social relations, increased substance use, and underachievement (Henin et al., 2005; Pavuluri et al., 1996). Because of the high rate of reported comorbidity between ADHD and BPSD (Biederman et al., 1996; Geller and Luby, 1997; Kowatch et al., 2005; Lewinsohn et al., 1995; Wozniak et al., 1995) the relationship between these two disorders has been widely studied and debated (Birmaher et al., 2010; Carlson, 1998; Egeland et al., 2003; Henin et al., 2007; Masi et al., 2006).

One approach to understanding the relationship between the two disorders is with family studies, which examine the risk of one family member having a disorder when another family member has the same or a related disorder. The two main types of studies are transgenerational (risk in offspring when parent or grandparent has a disorder or in parent when child has the disorder) and sibling comparisons, especially with monozygotic and dizygotic twins. From such associations it is not possible to separate genetic from environmental influences with certainty, although twin studies are suggestive. Family studies suggest that "bipolar disorder is phenotypically and genetically complex" (Smoller and Finn, 2003). Another approach is molecular genetic studies, which more directly address the genetic basis.

Although many studies did not control for confounding comorbid parental psychopathology, numerous family studies suggest a transgenerational association of manic and ADHD symptomatology. For example, the prevalence of bipolar disorder (BPD) has been reported to be much higher in relatives of youth with ADHD+BPD than in relatives of those with BPD without ADHD (Faraone et al., 2001). Conversely, offspring of parents with BP I or BP II were more likely to have a history of ADHD, anxiety, and oppositional defiant disorder or conduct disorder (ODD/CD) if they had BPD themselves than if they did not (Goldstein et al., 2009). However ADHD was no longer significantly associated with 
offspring BPD in multivariate models, whereas the association with anxiety disorders and ODD/CD remained significant.

Many, but not all, authors have reported a higher risk of ADHD in offspring of parents with BPSD. For example, children of parents with BPD were more likely to exhibit disruptive behaviors (between 22\% and 42\%) than children of control parents (between 3\% and 8\%) in a longitudinal study (Radke-Yarrow et al., 1992) and to have a higher rate of any disruptive behavior disorder, and ADHD in particular, compared to psychiatric and non-psychiatric control groups (Hirshfeld-Becker et al., 2006). Offspring of parents with bipolar disorder had three times the rate of ADHD as did offspring of control parents (Faraone et al., 1997) and eight times the population prevalence of ADHD, (Birmaher et al., 2010). Further, persistence of ADHD into adolescence and young adulthood was associated with parental mood disorders (Biederman et al., 2010). Among offspring of parents with BPD, children with ADHD or ODD had higher mania and depression scores than those without ADHD or ODD (Birmaher et al., 2010) and had a higher risk of later developing mood disorder (Nurnberger et al., 2011). However, other research failed to find increased rates of ADHD in offspring of parents with BPSD (Duffy et al., 2007; Hillegers et al., 2005).

Some of the positive findings may be explained by confounders or diagnostic methods: e.g., 6-18-year-old offspring of parents with BPD had higher rates of ADHD than offspring of controls in an unadjusted analysis, but that difference disappeared after controlling for confounding factors such as demographics and parent pathology (Birmaher et al., 2009). Further, among offspring of parents with BPD, rates of comorbid parental ADHD did not differ between offspring who had BPD vs. offspring who did not (Goldstein et al., 2009). Thus the literature at this point is not conclusive, but most published family studies favor an association within families of the two disorders, which may be partly explained by the symptom overlap of the disorders.

A review of molecular genetic studies did not disclose overlapping genes. Of five polymorphisms often reported to be involved in ADHD -DRD4, DRD5, dopamine transporter, serotonin transporter, and dopamine beta hydroxylase - (Bellgrove et al., 2006; Bobb et al., 2006), none have been implicated in BPSD. The closest in a long list of bipolar candidate genes was DRD1 (Kato, 2007). Thus family studies but not molecular genetic studies suggest an association between BPSD and ADHD.

These reports suggest testing the following hypotheses regarding family history in a new sample, the 707 children in the Longitudinal Assessment of Manic Symptoms (LAMS) study: (1) compared to children with neither BPSD nor ADHD, those with either BPSD or ADHD will have a higher rate of both bipolar and ADHD symptoms in their parents; (2) "comorbid" children (those with both BPSD and ADHD) will have even higher rates of BPSD and ADHD symptoms in their parents than children with BPSD alone or ADHD alone.

\section{Method}

\subsection{Study sites and participants}

Participants were from the NIMH-supported Longitudinal Assessment of Manic Symptoms (LAMS) study. All procedures were approved by the local university Institutional Review Boards. Written informed consent from the parents/guardians and assent from the children were obtained prior to data collection.

Participants were recruited from 9 child outpatient mental health clinics ( 2 in Cleveland, 1 in Pittsburgh, 5 in Columbus, and 1 in Cincinnati) associated with Case Western Reserve 
University, University of Pittsburgh, Ohio State University, and Cincinnati Children's Hospital. Eligible children were new evaluations ages 6-12 at the respective clinics. Parents/ guardians accompanying eligible children were asked to complete the Parent General Behavior Inventory - 10 Item Mania Scale (PGBI-10M) (Youngstrom et al., 2005, 2008) to screen for elevated symptoms of mania. The PGBI-10 M items, scored 0-3, describe hypomanic, manic, and biphasic symptoms and best discriminate bipolar disorder from other diagnoses (Youngstrom et al., 2005). Total scores range from 0 to 30. All patients whose parent/guardian rated them at or above 12 were invited to participate $(n=621)$. In addition, some patients with scores 11 or lower were selected by a matching procedure $(n=86)$. Details about subject ascertainment and the rationale for the cut score of 12 on the PGBI-10M are described separately (Horwitz et al., 2010).

\subsection{Assessment}

2.2.1. Diagnostic procedures-Participants were administered the Schedule for Affective Disorders and Schizophrenia for School-Age Children-Present and Lifetime Episode (Kaufman et al., 1997) with additional mood onset and offset items derived from the Washington University St. Louis Kiddie Schedule for Affective Disorders (Geller et al., 1998, 2001). ADHD diagnoses were made by the usual DSM-IV-TR criteria. As per DSMIV-TR, the category of BPSD included BP I, BP II, cyclothymic disorder, or bipolar not otherwise specified (BP-NOS). For any diagnosis of BPSD, we required episodes and did not count symptoms for ADHD that occurred only during episodes nor did we count symptoms for BPSD that were chronic ADHD symptoms; we attempted differential diagnoses.

BP I, BP II, and cyclothymic disorder all followed strict DSM-IV criteria. Because DSM has offered less specification about BP-NOS, the LAMS study used the following criteria for BP-NOS: (a) elated mood plus at least two associated symptoms of mania (e.g., grandiosity, decreased need for sleep, pressured speech, racing thoughts, increased goal-directed activity), or irritable mood plus at least three associated symptoms of mania; (b) change in the participant's level of functional competence (increase or decrease); (c) symptoms must be present for a total of at least $4 \mathrm{~h}$ within a 24-h period; and (d) the participant must have had at least four episodes of $4 \mathrm{~h}$ duration or a total of four days of the earlier-noted symptom intensity in his/her lifetime. These criteria were also used in the Course and Outcome of Bipolar Youth study (COBY) (Axelson et al., 2006). A licensed child psychiatrist or psychologist reviewed and confirmed all diagnoses. Inter-rater reliability was assured by the interviewers rating taped administrations of the K-SADS-PL-W, Children's Depression Rating Scale-Revised (CDRS-R) (Overholser et al., 1995; Poznanski et al., 1984), and the Young Mania Rating Scale (YMRS) (Young et al., 1978). The kappa for K-SADS-PL-W psychiatric diagnoses was 0.82 and more specifically, the kappa for bipolar diagnoses was 0.93. Additionally, demographic information including age, sex, race, ethnicity, and health insurance status were obtained from parents/guardians. A more detailed description of the assessment and description of the 707 children are outlined in Findling et al. (2010).

2.2.2. Measures of child symptom severity-"Unfiltered" manic symptoms (i.e., directly from informant with no attempt to classify symptoms into particular categories, in contrast to the "clinician-filtered" ratings used on the K-SADS described earlier) were assessed by parent report on the PGBI-10M, by clinician interview of child with the YMRS (Young et al., 1978), and by teacher-rated manic symptoms on the Child and Adolescent Symptom Inventory-4 - (CASI-4R), on which items are rated on a 0-3 scale (Gadow and Sprafkin, 1994). ADHD symptom severity was taken from the mean of the 18 ADHD symptoms on the CASI-4R rated by parent and teacher (Gadow and Sprafkin, 1994). 
2.2.3. Parental manic and ADHD symptoms-The Family History Screen (Milne et al., 2009; Weissman et al., 2000) collected information on 15 psychiatric disorders and suicidal behavior in biological parents. Symptoms of DSM-IV-TR defined mania were evaluated. Individuals were considered positive for a parental history of mania (PHM) if parents endorsed yes for "extreme elated mood" plus 3 supporting symptoms (more talkative, inflated self-esteem, decreased need for sleep, racing thoughts, more distractible than usual, more restless, and excessive involvement in pleasurable activities) or yes for extreme irritable mood with 4 supporting symptoms. In cases where there were missing data, if enough symptoms were known to meet the criteria mentioned, the parent was scored positively. If the parent could not meet criteria even if missing symptoms were available (e.g., if neither extreme elated mood nor extreme irritable mood was endorsed), the parent was scored negatively. If there was uncertainty regarding whether or not a parent would or would not meet criteria if missing symptoms were known, the parent was scored as unknown and that child was not included in this sample. ADHD symptoms in parents were assessed by a single question: In grade school, did the parent fidget, leave their seats when they weren't supposed to, not finish their schoolwork, or not pay attention to the teacher? If the parent responded yes, they were coded as positive for ADHD symptoms. Thus these parent symptom classifications are not based on a formal diagnostic examination of parents.

\subsection{Statistical analysis}

Descriptive statistics, including means and percentages, were computed for the demographic and diagnostic variables. Children and adolescents were divided into four diagnostic groups to be compared: ADHD without BPSD ("ADHD alone"), BPSD without ADHD ("BPD alone"), comorbid ADHD+ BPSD, and other or no diagnosis. Note that the word "alone" after ADHD or BPSD merely means without the other diagnosis, not necessarily without all comorbidity (e.g., there could be comorbid anxiety or conduct disorder). For these exploratory analyses, alpha was set at $\mathrm{p}<0.05$ for all analyses.

Two statistical approaches were used. First, chi-square analyses tested the stated hypothesis from the viewpoint of the child diagnosis, checking separately for symptoms in mothers, fathers, and "either parent".

The second set of analyses used regressions to explore the effect of parent symptoms on the severity of the child's symptoms and check on a possible effect of site. Specifically, regression analyses examined whether child diagnosis, parent symptoms, or the interaction of child diagnosis and parent symptoms predicted child ADHD or manic symptom severity reported by clinician, parent or teacher. The clinician-completed YMRS, the parentcompleted PGBI-10 M and the parent- and teacher-reported CASI-4 manic symptom subscale were used to measure child manic symptom severity. The parent- and teachercompleted CASI-4 ADHD combined subscales were used to examine child ADHD symptom severity. Hierarchical regressions entered any child BPSD diagnosis in the first step, then any parent history of manic symptoms, and then the interaction. Similarly, for ADHD, any child ADHD diagnosis was entered first, with parent history of ADHD symptoms entered second and the interaction with ADHD diagnosis entered last. Parent history and the interaction entered after child diagnosis in order to examine whether family history of mania/ADHD symptoms increased mania/ADHD symptom severity in the child after accounting for diagnosis. Inclusion of both the family history and its interaction with diagnosis allowed examination of whether family history increases symptoms independently or in combination with the presence of a diagnosis. After examining same construct relationships (e.g., bipolar diagnosis, parent history of manic symptoms, and their interaction predicting child mania symptom ratings), three additional steps were added to the hierarchical regressions. Additional steps examined cross-construct relationships (e.g., child 
ADHD diagnosis, parent history of ADHD symptoms, and their interaction predicting child mania symptom ratings). All analyses were also re-computed with site as a set of dummy codes.

\section{Results}

\subsection{Sample distribution}

Of the 707 children in the LAMS study at initial evaluation, $421(60 \%)$ had ADHD without BPSD ("ADHD alone"), 45 (6\%) had BPSD without ADHD ("BPD alone"), 117 (17\%) had comorbid ADHD and BPSD, and 124 (18\%) had neither ADHD nor BPSD. Of the 638 with family history data for at least one parent, $380(60 \%)$ had ADHD without BPSD ("ADHD alone"), 41(6\%) had BPSD without ADHD ("BPD alone"), 108 (17\%) had comorbid ADHD and BPSD, and 109 (17\%) had neither ADHD nor BPSD. Thus the distribution by child diagnosis for those with parent data was not different from the distribution for the whole sample.

\subsection{Hypothesis testing}

As reported in Table 1 and illustrated in Fig. 1, differences among the four groups were significant on omnibus tests for either parent with manic symptoms, mothers with mania, and fathers with mania (all $\mathrm{p} \unlhd \mathbf{0 . 0 0 1}$ ). In addition, the omnibus test was significant for either parent with ADHD symptoms $(\mathrm{p}=0.04)$ but not for just mothers or just fathers with ADHD symptoms (although fathers had a marginal trend, $p=0.09$ ). In subsequent pairwise comparisons, significantly more mothers of BPSD-alone children (26\%) and comorbid children (23\%) had manic symptoms than mothers of children with only ADHD (10\%) or neither diagnosis (9\%). Results were comparable for fathers, except that the comparison of fathers of comorbid children to fathers of children with ADHD alone was not significant ( $13 \%$ vs. $8 \%, p=0.08)$. The results for "either parent" were similar to those for mothers but more pronounced (all $\mathrm{p}<0.001)$. The only significant differences in parental ADHD symptoms were between fathers of ADHD-alone (20\%) compared to BPSD-alone (7\%) children and for either parent of BPSD alone (15\%) compared to parents of ADHD alone (30\%) and parents of comorbid ADHD+BPSD (32\%).

Table 2 presents the results of hierarchical regression analyses for manic and ADHD symptom ratings. As expected, being diagnosed with a bipolar spectrum disorder was a strong predictor of child manic-symptom severity on the YMRS even when family history and the interaction between family history and diagnosis were considered $\left(\mathrm{R}^{2}=0.283, \beta=\right.$ $0.56, \mathrm{t}(632)=13.71, \mathrm{p}<0.001)$. However, neither family history nor the interaction of family history with child BPSD diagnosis predicted manic symptom severity on the YMRS. Slightly different results were found with the PGBI-10M. Diagnosis continued to be a strong predictor of manic symptoms when family history and its interaction with diagnosis were taken into account $\left(\mathrm{R}^{2}=0.098\right.$, BP diagnosis $\left.\beta=0.30, \mathrm{t}(618)=6.59, \mathrm{p}<0.001\right)$. However, the presence of any parental history of manic symptoms was associated with a significant increase in child manic symptoms after accounting for diagnosis $\left(\Delta \mathrm{R}^{2}=0.024, \mathrm{p}<0.001\right.$; Family history $\beta=0.19, \mathrm{t}(618)=3.99, \mathrm{p}<0.001$ ). This effect was consistent across youth with and without BP diagnoses, as the interaction of family history and diagnosis was not significant $\left(\Delta \mathrm{R}^{2}=0.002, \mathrm{~F}(1,618)=1.13, \mathrm{p}=0.289\right)$. The same pattern was found on the CASI-4 parent report manic symptom subscale: diagnosis was a strong predictor of higher manic symptoms when family history and its interaction were included $\left(R^{2}=0.117, \beta=\right.$ $0.31, \mathrm{t}(617)=6.99, \mathrm{p}<0.001)$; and family history contributed to increased manic symptoms beyond diagnosis $\left(\Delta R^{2}=0.041, p<0.001, \beta=0.23, t(617)=4.92, p<0.001\right)$. This effect was maintained in those participants with and without a BP diagnosis because the interaction was not significant $\left(\Delta \mathrm{R}^{2}=0.001, \mathrm{~F}(1,617)=-0.82, \mathrm{p}=0.412\right)$. Teacher reported manic 
symptoms on the CASI-4 manic symptoms subscale were not predicted by diagnosis, family history, or their interaction (largest $(\mathrm{t}(422)=-0.63, \mathrm{p}=0.560)$. Having an ADHD diagnosis significantly increased parent and teacher-rated manic symptoms (smallest $\mathrm{t}(617)=2.73, \mathrm{p}=$ $0.007)$, with a marginal trend on the clinician-rated YMRS $(\mathrm{t}(631)=1.77, \mathrm{p}=0.078)$.

Family history of ADHD symptoms did not significantly predict manic symptom severity across any measure (largest $\mathrm{t}(419)=1.83, \mathrm{p}=0.078)$.

Child diagnosis of ADHD was also a robust predictor of greater child ADHD symptoms on the CASI-4 ADHD parentrated subscale even when family history of ADHD symptoms and the interaction between family history and diagnosis were taken into account $\left(R^{2}=0.205, \beta\right.$ $=0.44, \mathrm{t}(618)=11.29, \mathrm{p}<0.001)$. However, neither family history nor the interaction of family history by child diagnosis increased the prediction of parent-reported ADHD symptoms $\left(\Delta \mathrm{R}^{2}=0.004, \mathrm{t}(618)=0.23, \mathrm{p}=0.820\right.$ and $\Delta \mathrm{R}^{2}<0.001, \mathrm{t}(618)=0.67, \mathrm{p}=0.555$ respectively). Having a bipolar spectrum diagnosis $(\beta=0.22, \mathrm{t}(615)=5.49, \mathrm{p}<0.001)$ or a family history of mania $(\beta=0.15, \mathrm{t}(615)=2.51, \mathrm{p}=0.014)$ also increased parent-reported ADHD symptoms. Interestingly, having both a bipolar spectrum diagnosis and a family history of mania significantly decreased parent-reported ADHD symptoms $(\beta=-0.11$, $\mathrm{t}(615)=-2.07, \mathrm{p}=0.039)$, possibly indicating greater rating clarity regarding the difference between bipolar and ADHD symptoms when a parent has bipolar disorder. Diagnosis was also a strong predictor of greater teacher- rated ADHD symptoms on the CASI-4, even when family history and the interaction between family history \& diagnosis were considered $\left(\mathrm{R}^{2}=\right.$ $0.111, \beta=0.28, \mathrm{t}(419)=5.65, \mathrm{p}<0.001)$. After accounting for diagnosis, family history of ADHD symptoms was associated with greater teacher-rated ADHD symptoms $\left(\Delta \mathrm{R}^{2}=\right.$ $0.011, \beta=0.10, t(419)=2.35, p=0.019)$. Because the interaction of family history by child diagnosis did not significantly increase the prediction of teacher-rated ADHD symptoms $\left(\Delta R^{2}=0.007, F(1,419)=3.71, p=0.055\right)$, these results were generally consistent in children with and without an ADHD diagnosis. Having a bipolar diagnosis, family history of manic symptoms, or both did not significantly influence teacher reports of ADHD symptoms (largest $\mathrm{t}(416)=-0.53, \mathrm{p}=0.641)$.

Site accounted for a small proportion of the variance in each symptom measure (range $0.2 \%-6.0 \%)$. The pattern of results was unchanged when site was included as an additional predictor in the regression models (for both manic and ADHD symptoms). Because there was no reason to suspect that site would affect the relationship of parent symptoms to child symptom severity, we present the results without adjusting for site.

\section{Discussion}

In this clinical sample of 707 outpatients, enriched with children whose parent scored them above 12 on the GBI-S10M at their first clinic visit, the majority (76\%) had ADHD and a substantial proportion (23\%) had BPSD (diagnosed with a requirement for episodes): $17 \%$ of the sample had comorbid ADHD and BPSD, which would be expected by chance. The proportions with each diagnosis were nearly identical for the subgroup of 638 with usable parent symptom data.

Regarding the hypothesis of greater rate of manic symptoms in parents of children with either BPSD or ADHD (compared to children with neither diagnosis) and even greater rates for comorbid children, the difference by child diagnosis is very clear. Both mothers and fathers of children with BPSD but not parents of children with ADHD alone had greater rates of manic symptoms than parents of children with neither diagnosis. Further, parents of children with BPSD had greater rates of manic symptoms than parents of children with ADHD alone. Moreover, parents of comorbid children had no greater rate of manic symptoms than parents of children with BPSD alone. Thus parental manic symptoms were 
associated only with child BPSD, not child ADHD. In fact, for both mothers and fathers, the comorbid group had nominally lower rates of parental manic symptoms than were reported for the BPSD alone group. A possible explanation for this surprising result could be that without the troublesome ADHD symptoms, it might take more familial awareness of mood symptoms (as from a parent having BPSD) to precipitate child referral (Youngstrom et al., 2011).

Regarding the hypotheses of greater rate of ADHD symptoms in parents of children with ADHD or BPSD, and even higher rates for comorbid children, compared to children with neither diagnosis, the results are not as clear, but consistent with the difference by child diagnosis found for parental manic symptoms. The omnibus test for differences among child diagnostic groups was significant only by the greater power of the "either parent" analysis, and that only barely $(\mathrm{p}=0.04)$; the omnibus tests for mothers and fathers separately were not significant. Scrutiny of the descriptive statistics shows a tendency for a greater rate of ADHD symptoms in parents of children with ADHD, but not in parents of children with BPSD alone, compared to those with neither diagnosis, and the comorbid group shows no tendency for higher parent rates of ADHD symptoms than the ADHD-alone group.

Thus parental symptomatology specifically matched the child symptomatology for both manic and ADHD symptoms - separately.

The opposite analytic strategy, examining child symptom severity by parental symptom type, yielded compatible results. Regression analyses revealed that the family history of manic symptoms predicts child manic symptom severity over and above child diagnosis for parent rating but not teacher rating. Family history of ADHD symptoms significantly predicted teacher rating of child ADHD symptoms severity, but not significantly for parent report. These chiasmic results can be explained by teachers being more attuned to ADHD than to BPSD in their work and in a better position to observe ADHD severity, while parents who are familiar with BPSD because of family history are more attuned to rating manic symptoms and have less opportunity to observe ADHD severity. The association of parent manic symptoms with parent-rated child ADHD severity is at least partly due to a significant interaction of child diagnosis with parent symptoms. Importantly, family history of ADHD symptoms did not significantly predict child manic symptom severity on any measure rated by parent, teacher, or clinician.

The failure of teacher ratings of child manic symptom severity to be associated with parental manic symptoms while parental ratings of child manic symptom severity did associate with parental symptoms recalls two compatible recent reports about informant differences. Carlson and Blader (2011) found that teacher ratings on the Child Mania Rating Scale added no diagnostic accuracy for child bipolar 1 or 2 disorders, and parent and teacher concordance was associated with child externalizing disorders more than with bipolar diagnosis. Arnold et al. (2011) reported that in contrast to parents, teachers rated child manic symptoms worse in the comorbid group than in BPSD alone, but not worse than in ADHD. These three separate findings would be compatible with teachers conflating manic and ADHD symptoms. These results do not support familial linking of BPSD and ADHD. This finding is compatible with Birmaher's report that for youth age 6-18 years, offspring of BPD parents did not have higher rates of ADHD compared to offspring of parents with nonBPD psychopathology, only higher rates compared to offspring of healthy control parents (Birmaher et al., 2009). The results are also compatible with the finding that children in this sample did not show greater comorbidity than expected by chance (Arnold et al., 2011). These findings are also consistent with the conclusions of a recent review of the ADHDbipolar comorbidity literature (Galanter and Leibenluft, 2008) and the possibility that there are some shared "components" but not a linkage at the global diagnostic level (Youngstrom 
et al., 2010). The reason for variance from some other reports in this regard may lie with differences in diagnostic procedures. In this study, we made a clean distinction between ADHD and BPSD by requiring episodes and at least some peculiarly bipolar symptoms for the latter and by not counting symptoms for an ADHD diagnosis if they occurred only during a mood episode.

\subsection{Limitations}

The data presented here were collected cross-sectionally, so any conclusions about longitudinal course, progression, or causality must be considered speculative. The same sample is being followed with periodic assessments that will allow conclusions about progression and course in the future. The parent symptoms were based on simple questionnaire items about symptoms in the parents: the parent ADHD question was particularly weak, consisting of a single question listing 4 characteristic symptoms; this could lead to either over- or under-suspicion of parental ADHD. The assessment of parental manic symptoms was more detailed, with several symptoms separately inquired about and a more rigorous algorithm used, but not a formal diagnostic interview. However, the over- or under-sensitivity to parental symptoms should have affected all probands similarly so that the comparisons between subgroups should still be valid. An inherent weakness of this study is the method of sample collection, which was designed for a different purpose. It was neither epidemiologically representative of the whole child population nor representative of the whole child mental health clinic population. Rather, it is a screen-enriched cohort mainly representative of the subgroup of the child mental health clinic population that presents at first appointment with elevated symptoms of mania. For this reason, the proportions with BPSD and with ADHD (for which most - perhaps all — symptoms are similar to bipolar symptoms) are probably higher than in the general child mental health clinical population. Nevertheless, the actual diagnoses were carefully made by experienced research diagnosticians using information from reliability-trained interviewers, so that the comparisons between diagnoses should be valid. The small number (41) with BPSD without ADHD impaired power for some comparisons, possibly allowing some Type 2 errors. Power was strong for omnibus tests involving the full sample, with power $>0.8$ to detect fairly small effects (e.g., Cohen's w $=0.13$ ). However, pairwise comparisons focused on the rarer subgroups were only powered to detect large effects (e.g., Cohen's $w=0.33$ or greater) (Faul et al., 2009). Conversely, using 0.05 as the significance level with multiple tests increased the risks of Type 1 error. However, the significant findings for manic symptoms (mostly $\mathrm{p}<0.001)$ would have withstood correction for multiple tests. Further, in reporting a null finding (lack of familial association), Type 2 error requires most guarding against, so the alpha of 0.05 seems appropriate.

Thus this carefully characterized sample of children from mental health clinics show significant association between parent and child psychopathology within diagnostic category, but not the suspected "crossing over" of ADHD and manic symptoms transgenerationally. Compared with children who have only ADHD and "neutral" children with neither BPSD nor ADHD, children with BPSD, either with or without ADHD, had more parents with manic symptoms but not more with ADHD symptoms, and the comorbid group did not have more parents with manic symptoms than the BPSD-alone group. Conversely, children with ADHD had more parents with ADHD symptoms, but not more with manic symptoms, and comorbid children had no more parents with ADHD symptoms than did those with ADHD alone. The two disorders seemed to "breed true," contrary to the expectation of transgenerational synergism of symptomatology. 


\section{Acknowledgments}

This study was supported by NIMH awards: Case Western Reserve University: R01 MH073967-06A1; Children's Hospital Medical Center, Cincinnati: R01 MH073816-06A1; The Ohio State University: R01 MH073801-06A1; and University of Pittsburgh: R01 MH073953-06A1.

\section{Role of funding source}

The LAMS study was supported by the National Institute of Mental Health (NIMH). The funders had no role in study design, data collection and analysis, or in the decision to submit this paper for publication.

\section{References}

Arnold LE, Demeter C, Mount K, Frazier TW, Youngstrom EA, Fristad M, Birmaher B, Findling RL, Horwitz AM, Kowatch R, Axelson DA. Pediatric bipolar spectrum disorder and ADHD: comparison and comorbidity in the LAMS clinical sample. Bipolar Disorders. 2011; 13:509-521. [PubMed: 22017220]

Axelson DA, Birmaher B, Strober M, Gill M, Valeri S, Chiappetta L. Phenomenology of children and adolescents with bipolar spectrum disorders. Archives of General Psychiatry. 2006; 63:1139-1148. [PubMed: 17015816]

Bellgrove MA, Hawi Z, Gill M, Robertson IH. The cognitive genetics of attention deficit hyperactivity disorder (ADHD): sustained attention as a candidate phenotype. Cortex. 2006; 42:838-845. [PubMed: 17131588]

Biederman J, Faraone S, Mick E, Wozniak J, Chen L, Ouellette C, Marrs A, Moore P, Garcia J, Mennin D, Lelon E. Attention-deficit and hyperactivity disorder and juvenile mania: an over-looked comorbidity? Journal of the American Academy of Child and Adolescent Psychiatry. 1996; 35:9971008. [PubMed: 8755796]

Biederman J, Petty CR, Evans M, Small J, Faraone SV. How persistent is ADHD? A controlled 10year follow-up study of boys with ADHD. Psychiatry Research. 2010; 177:299-304. [PubMed: 20452063]

Birmaher B, Axelson D, Monk K, Kalas C, Goldstein B, Hickey M, Obreja M, Ehmann M, Iyengar S, Shamseddeen W, Kupfer D. Lifetime psychiatric disorders in school-aged offspring of parents with bipolar disorder: the Pittsburgh bipolar offspring study. Archives of General Psychiatry. 2009; 66:287-296. [PubMed: 19255378]

Birmaher B, Axelson DA, Goldstein B, Monk K, Kalas C, Obreja M, Hickey M, Iyengar S, Brent D, Shamseddeen W, Diler R, Kupfer D. Psychiatric disorders in preschool offspring of parents with bipolar disorder: the Pittsburgh bipolar offspring study (BIOS). The American Journal of Psychiatry. 2010; 167:321-330. [PubMed: 20080982]

Bobb AJ, Castellanos FX, Addington AM, Rapoport JL. Molecular genetic studies of ADHD: 1991 to 2004. American Journal of Medical Genetics. Part B. 2006; 141:551-565.

Carlson GA. Mania and ADHD: comorbidity or confusion. Journal of Affective Disorders. 1998; 51:177-187. [PubMed: 10743850]

Carlson GA, Blader JC. Diagnostic implications of informant disagreement for manic symptoms. Journal of Child and Adolescent Psychopharmacology. 2011; 21:399-405. [PubMed: 22040185]

Duffy A, Alda M, Crawford L, Milin R, Grof P. The early manifestations of bipolar disorder: a longitudinal prospective study of the offspring of bipolar parents. Bipolar Disorders. 2007; 9

Egeland J, Shaw J, Endicott J, Pauls D, Allen C, Hostetter A, Sussex J. Prospective study of prodromal features for bipolarity in well Amish children. Journal of the American Academy of Child and Adolescent Psychiatry. 2003; 42:786-796. [PubMed: 12819438]

Faraone S, Biederman J, Mennin D, Wozniak J, Spener T. Attention-deficit hyperactivity disorder with bipolar disorder: a familial subtype? Journal of the American Academy of Child and Adolescent Psychiatry. 1997; 36:1378-1387. [PubMed: 9334551]

Faraone S, Biederman J, Monuteaux M. Attention deficit hyperactivity disorder with bipolar disorder in girls: further evidence for a familial subtype? Journal of Affective Disorders. 2001; 64:19-26. [PubMed: 11292516] 
Faul F, Erdfelder E, Buchner A, Lang A. Statistical power analyses using G*Power 3.1: tests for correlation and regression analyses. Behavior Research Methods. 2009; 41:1149-1160. [PubMed: 19897823]

Findling R, Youngstrom E, Fristad M, Birmaher B, Kowatch RA, Arnold LE, Frazier TW, Axelson D, Ryan N, Demeter C, Gill M, Fields B, Depew J, Kennedy SM, Marsh L, Rowles BM, Horwitz SM. Characteristics of children with elevated symptoms of mania: the longitudinal assessment of manic symptoms (LAMS) study. The Journal of Clinical Psychiatry. 2010; 71:1664-1672. [PubMed: 21034685]

Gadow, K.; Sprafkin, J. Child Symptom Inventories Manual. Checkmate Plus; Stony Brook, NY: 1994.

Galanter C, Leibenluft E. Frontiers between attention deficit hyperactivity disorder and bipolar disorder. Child and Adolescent Psychiatric Clinics of North America. 2008; 17:325-346. [PubMed: 18295149]

Geller B, Luby J. Child and adolescent bipolar disorder: a review of the past 10 years. Journal of the American Academy of Child and Adolescent Psychiatry. 1997; 36:1168-1176. [PubMed: 9291717]

Geller B, Warner K, Williams M, Zimerman B. Prepubertal and young adolescent bipolarity versus ADHD: assessment and validity using the WASH-U-KSADS, CBCL and TRF. Journal of Affective Disorders. 1998; 51:93-100. [PubMed: 10743842]

Geller B, Zimerman B, Williams M, Bolhofner K, Craney JL, DelBello MP, Soutullo C. Reliability of the Washington University in St. Louis kiddie schedule for affective disorders and schizophrenia (WASH-U-KSADS) mania and rapid cycling sections. Journal of the American Academy of Child and Adolescent Psychiatry. 2001; 40:450-455. [PubMed: 11314571]

Goldstein B, Shamseddeen W, Axelson D, Kalas C, Monk K, Brent D, Kupfer MD, Birmaher B. Clinical, demographic, and familial correlates of bipolar spectrum disorders among offspring of parents with bipolar disorder. Journal of the American Academy of Child and Adolescent Psychiatry. 2009; 49:388-396. [PubMed: 20410731]

Henin A, Biederman J, Mick E, Sachs G, Hirshfeld-Becker D, Siegel R, McMurrich S, Grandin L, Nierenberg AA. Psychopathology in the offspring of parents with bipolar disorder: a controlled study. Biological Psychiatry. 2005; 58:554-561. [PubMed: 16112654]

Henin A, Biederman J, Mick E, Hirshfeld-Becker D, Sachs G, Wu Y, Yan L, Ogutha J, Nierenberg AA. Childhood antecedent disorders to bipolar disorder in adults: a controlled study. Journal of Affective Disorders. 2007; 99:51-57. [PubMed: 17045657]

Hillegers MH, Reichart CG, Wals M, Verhulst FC, Ormel J, Nolen WA. Five-year prospective outcome of psychopathology in the adolescent offspring of bipolar parents. Bipolar Disorders. 2005; 7:344-350. [PubMed: 16026487]

Hirshfeld-Becker D, Biederman J, Henin A, Faraone SV, Dowd ST, De Petrillo LA, Markowitz SM, Rosenbaum JF. Psychopathology in the young offspring of parents with bipolar disorder: a controlled pilot study. Psychiatry Research. 2006; 145:155-167. [PubMed: 17083985]

Horwitz SM, Demeter C, Pagano ME, Youngstrom EA, Fristad MA, Arnold LE, Birmaher B, Gill M, Axelson D, Kowatch RA, Frazier TW, Findling RL. Longitudinal assessment of manic symptoms (LAMS) study: background, design and initial screening results. The Journal of Clinical Psychiatry. 2010; 71:1511-1517. [PubMed: 21034684]

Kato T. Molecular genetics of bipolar disorder and depression. Psychiatry and Clinical Neurosciences. 2007; 61:3-19. [PubMed: 17239033]

Kaufman J, Birmaher B, Brent D, Rao U, Flynn C, Moreci P, Williamson D, Ryan N. Schedule of affective disorders and schizophrenia for school-age children-present and lifetime version (KSADS-PL): initial reliability and validity data. Journal of the American Academy of Child and Adolescent Psychiatry. 1997; 36:980-988. [PubMed: 9204677]

Kowatch R, Youngstrom E, Danielyan A, Findling R. Review and meta-analysis of the phenomenology and clinical characteristics of mania in children and adolescents. Bipolar Disorders. 2005; 7:483-496. [PubMed: 16403174] 
Lewinsohn P, Klein D, Seeley J. Bipolar disorders in a community sample of older adolescents: prevalence, phenomenology, comorbidity, and course. Journal of the American Academy of Child and Adolescent Psychiatry. 1995; 34:454-463. [PubMed: 7751259]

Masi G, Perugi G, Toni C, Millepiedi S, Mucci M, Bertini N, Pfanner C. Attention-deficit hyperactivity disorder — bipolar comorbidity in children and adolescents. Bipolar Disorders. 2006; 8:373-381. [PubMed: 16879138]

Milne B, Caspi A, Harrington H, Poulton R, Rutter M, Moffitt T. Predictive value of family history on severity of illness. Archives of General Psychiatry. 2009; 66:738-747. [PubMed: 19581565]

Nurnberger JI, McInnis M, Reich W, Kastelic E, Wilcox HC, Glowinski A, Mitchell P, Fisher C, Erpe M, Gershon ES, Berrettini W, Laite G, Schweitzer R, Rhoadarmer K, Coleman VV, Cai X, Azzouz F, Liu H, Kamali M, Brucksch C, Monahan OO. A high-risk study of bipolar disorder: childhood clinical phenotypes as precursors of major mood disorders. Archives of General Psychiatry. 2011; 68:1012-1020. [PubMed: 21969459]

Overholser JC, Brinkman DC, Lehnert KL, Ricciardi AM. Children's depression rating scalerevised: development of a short form. Journal of Clinical Child Psychology. 1995; 24:443-452.

Pavuluri MN, O'Connor MM, Harral EM, Moss M, Sweeney JA. Impact of neurocognitive function on academic difficulties in pediatric bipolar disorder: a clinical translation. Biological Psychiatry. 1996; 60:951-956. [PubMed: 16730333]

Poznanski EO, Grossman JA, Buchsbaum Y, Banegas M, Freeman L, Gibbons R. Preliminary studies of the reliability and validity of the children's depression rating scale. Journal of the American Academy of Child Psychiatry. 1984; 23:191-197. [PubMed: 6715741]

Radke-Yarrow M, Nottelmann E, Martinez P, Fox M, Belmont B. Young children of affectively ill parents: a longitudinal study of psychosocial development. Journal of the American Academy of Child and Adolescent Psychiatry. 1992; 31:68-77. [PubMed: 1537784]

Smoller JW, Finn CT. Family, twin, and adoption studies of bipolar disorder. American Journal of Medical Genetics. Part C, Seminars 0in Medical Genetics. 2003; 123:48-58.

Weissman MM, Wickramaratne P, Adams P, Wolk S, Verdeli H, Olfson M. Brief screening for family psychiatric history: the family history screen. Archives of General Psychiatry. 2000; 57:675-682. [PubMed: 10891038]

Wozniak J, Biederman J, Kiely K, Ablon J, Faraone S, Mundy E, Mennin D. Mania-like symptoms suggestive of childhood-onset bipolar disorder in clinically referred children. Journal of the American Academy of Child and Adolescent Psychiatry. 1995; 34:867-876. [PubMed: 7649957]

Young RC, Biggs JT, Ziegler VE, Meyer DA. A rating scale for mania: reliability, validity and sensitivity. The British Journal of Psychiatry. 1978; 133:429-435. [PubMed: 728692]

Youngstrom EA, Meyers O, Demeter C, Youngstrom J, Morello L, Piiparinen R, Feeny N, Calabrese JR, Findling RL. Comparing diagnostic checklists for pediatric bipolar disorder in academic and community mental health settings. Bipolar Disorders. 2005; 7:507-517. [PubMed: 16403176]

Youngstrom EA, Frazier TW, Demeter C, Calabrese JR, Findling RL. Developing a 10-item mania scale from the parent general behavior inventory for children and adolescents. The Journal of Clinical Psychiatry. 2008; 69:831-839. [PubMed: 18452343]

Youngstrom EA, Arnold LE, Frazier TW. Bipolar and ADHD comorbidity: both artifact and outgrowth of shared mechanisms. Clinical Psychology: Science and Practice. 2010; 17:350-359. [PubMed: 21278822]

Youngstrom EA, Youngstrom JK, Freeman AJ, De Los Reyes A, Feeny NC, Findling RL. Informants are not all equal: predictors and correlates of clinician judgments about caregiver and youth credibility. Journal of Child and Adolescent Psychopharmacology. 2011; 21:407-415. [PubMed: 22040186] 


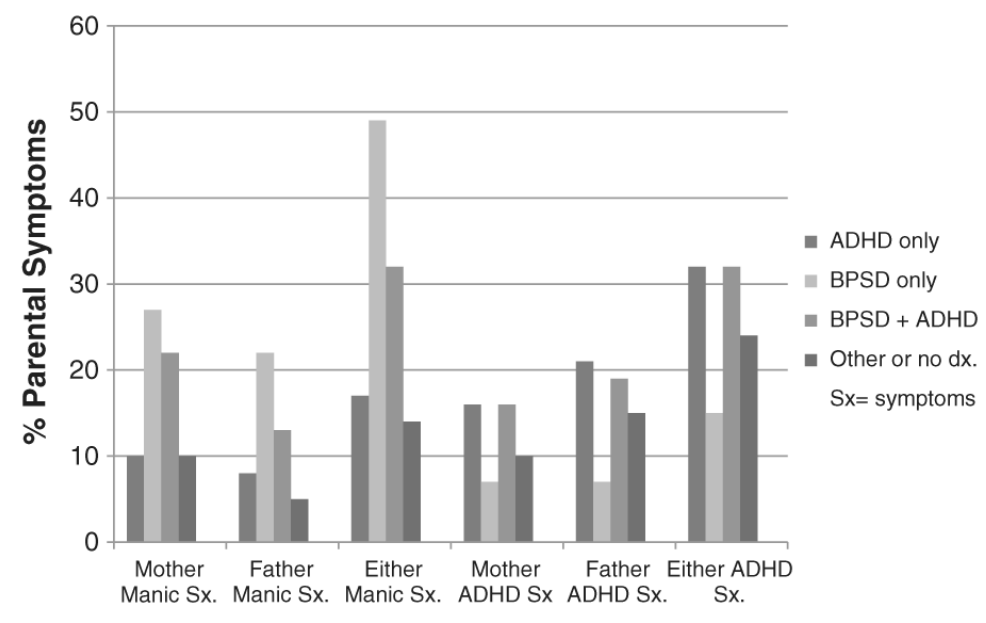

Fig. 1.

Percent of each child diagnostic group with parental manic or ADHD symptoms. 
Table 2

Hierarchical regression analyses for child manic and ADHD symptom severity.

\begin{tabular}{|c|c|c|c|c|c|}
\hline Child symptom rating & Independent variable & $\Delta \mathbf{R}^{2}$ & B & SE & $\mathbf{t}(\mathbf{p})$ \\
\hline \multirow[t]{6}{*}{ YMRS } & Any BP dx? & 0.283 & 12.6 & 0.9 & $13.7(<0.001)$ \\
\hline & Any parent manic $\mathrm{Sx}$ ? & 0.001 & 1.5 & 1.0 & $1.5(0.135)$ \\
\hline & Interaction & 0.003 & -2.6 & 1.7 & $-1.6(0.119)$ \\
\hline & Any ADHD dx.? & 0.004 & 1.3 & 0.7 & $1.8(0.078)$ \\
\hline & Any parent ADHD Sx? & $<0.001$ & 0.4 & 0.7 & $0.6(0.560)$ \\
\hline & Interaction & 0.001 & 1.9 & 1.7 & $1.1(.278)$ \\
\hline \multirow[t]{6}{*}{ PGBI-10M } & Any BP dx? & 0.098 & 5.2 & 0.8 & $6.6(<0.001)$ \\
\hline & Any parent manic $\mathrm{Sx}$ ? & 0.024 & 3.4 & 0.9 & $4.0(<0.001)$ \\
\hline & Interaction & 0.002 & -1.5 & 1.4 & $-1.1(0.289)$ \\
\hline & Any ADHD dx? & 0.010 & 1.7 & 0.6 & $2.7(0.007)$ \\
\hline & Any parent ADHD Sx? & $<0.001$ & -0.1 & 0.6 & $<0.2(0.862)$ \\
\hline & Interaction & $<0.001$ & -0.5 & 1.5 & $-0.3(0.733)$ \\
\hline \multirow[t]{6}{*}{ CASI-4R parent rating of manic $S x$} & Any BP dx? & 0.117 & 4.4 & 0.6 & $7.0(<0.001)$ \\
\hline & Any parent manic $\mathrm{Sx}$ ? & 0.041 & 3.4 & 0.7 & $4.9(<0.001)$ \\
\hline & Interaction & 0.001 & -1.0 & 1.2 & $-0.8(0.412)$ \\
\hline & Any ADHD dx? & 0.019 & 1.9 & 0.5 & $3.7(<0.001)$ \\
\hline & Any parent ADHD Sx? & 0.002 & 0.6 & 0.5 & $1.1(0.265)$ \\
\hline & Interaction & $<0.001$ & 0.4 & 1.3 & $0.3(0.744)$ \\
\hline \multirow[t]{6}{*}{ CASI-4R teacher rating of manic $\mathrm{Sx}$} & Any BP dx? & $<0.001$ & 0.15 & 0.8 & $0.2(0.844)$ \\
\hline & Any parent manic $\mathrm{Sx}$ ? & 0.001 & $<0.5$ & 0.8 & $-0.6(0.560)$ \\
\hline & Interaction & $<0.001$ & 0.2 & 1.5 & $0.1(0.901)$ \\
\hline & Any ADHD dx? & 0.052 & 3.0 & 0.6 & $4.8(<0.001)$ \\
\hline & Any parent ADHD Sx? & 0.007 & 1.1 & 0.6 & $1.8(0.078)$ \\
\hline & Interaction & 0.005 & 2.3 & 1.5 & $1.5(0.142)$ \\
\hline \multirow[t]{6}{*}{ CASI-4R Parent Rating of ADHD Sx } & Any ADHD dx? & 0.205 & 12.3 & 1.1 & $11.3(<0.001)$ \\
\hline & Any parent ADHD Sx? & 0.004 & 0.5 & 2.2 & $0.2(0.820)$ \\
\hline & Interaction & $<0.001$ & 1.4 & 2.4 & $0.6(0.555)$ \\
\hline & Any BP dx? & .036 & 5.5 & 1.0 & $5.4(<0.001)$ \\
\hline & Any parent manic $\mathrm{Sx}$ ? & 0.007 & 2.7 & 1.1 & $2.5(0.014)$ \\
\hline & Interaction & 0.005 & -4.7 & 2.3 & $-2.1(0.039)$ \\
\hline \multirow[t]{6}{*}{ CASI- $4 \mathrm{R}$ teacher rating of ADHD Sx } & Any ADHD dx.? & 0.111 & 9.3 & 1.7 & $5.7(<0.001)$ \\
\hline & Any parent ADHD Sx? & 0.011 & 3.2 & 1.4 & $2.3(0.019)$ \\
\hline & Interaction & 0.007 & 7.1 & 3.7 & $1.9(0.055)$ \\
\hline & Any BP dx? & $<0.001$ & -0.7 & 1.6 & $-0.5(0.641)$ \\
\hline & Any parent manic $\mathrm{Sx}$ ? & $<0.001$ & -0.1 & 1.7 & $-0.1(0.964)$ \\
\hline & Interaction & 0.001 & -0.9 & 2.0 & $-0.4(0.674)$ \\
\hline
\end{tabular}

Note. Any BP dx and Any ADHD dx refer to diagnoses in the youth; "Any parent manic sx" and "Any parent ADHD sx" refer to history of symptoms in the parent. All analyses presented in order of hierarchical entry into the model. 